\title{
ON THE BONDING STRENGTH OF FE-BASED SELF-FLUXING ALLOY COATING DEPOSITED BY DIFFERENT METHODS ON THE STEEL SUBSTRATE
}

\author{
E. FELDSHTEIN ${ }^{*}$ \\ Institute of Mechanical Engineering and Machine Operation \\ University of Zielona Góra \\ ul. Prof. Z. Szafrana 4 \\ 65-516 Zielona Góra, POLAND \\ E-mail: E.Feldsztein@ibem.uz.zgora.pl \\ M. KARDAPOLAVA \\ Faculty of Mechanical Engineering \\ Belarusian National Technical University \\ Khmelnitsky str., 9, build. 6, 220013, Minsk, BELARUS \\ O. DYACHENKO \\ Marketing, Management and Entrepreneurship Faculty \\ Belarusian National Technical University \\ Nezavisimosty Ave, 65, build. 18a, 220013, Minsk, BELARUS
}

\begin{abstract}
In the present paper, the bonding strength of Fe-based self-fluxing alloy coating deposited by plasma spraying, gluing and laser remelting and alloying on the steel substrate have been investigated. When flame melting, a globular structure is formed. Against the background of the solid solution carbide-boride phases are clearly distinguishable, between which the $\mathrm{Fe}-\mathrm{Fe}_{2} \mathrm{~B}$ and $\mathrm{Fe}-\mathrm{FeB}$ eutectic colonies are situated. Laser remelting leads to the formation of metastable structures, reinforced with dendrites, consisting of alloyed $\mathrm{Fe}-\alpha$ and $\mathrm{Fe}-\gamma$. At the low laser beam speeds the coating is melted completely with the formation of a cast structure with the dendrites. When the laser beam speed is increased, the dendritic structure gets fragmented. Structures of coatings alloyed with $\mathrm{B}_{4} \mathrm{C}$ and remelted by the laser beam vary with the increase of the spot speed. The bonding strength of coating without subsequent remelting decreases by $4-5$ times in comparison with remelted. The bonding strength of the reinforced glue coating has adhesive and adhesive-cohesive character. When the load increases in the coating, microcracks develop, which gradually spread to the center of the bonding surface. For plasma coatings after laser remelting without additional alloying, the maximum bonding strength is observed with the minimum laser beam speed. With increasing the laser beam speed it decreases almost 1.5 times. In glue coatings reinforced with $\mathrm{B}_{4} \mathrm{C}$ particulates by laser remelting, the bonding strength is lower by 1.2-1.4 times in comparison with plasma coating.
\end{abstract}

Key words: Fe-based self-fluxing alloy, coating, plasma spraying, laser remelting, bonding strength.

\section{Introduction}

The surface condition of machine parts affects many of their properties. An optimum combination of properties of the part material usually represents a compromise between the required surface operational characteristics (wear resistance, corrosion resistance, etc.) and the necessary material properties (strength, toughness, etc.). Parts with optimal properties can be produced by improving their surface processing technology, including coating. From among the various coating technologies plasma spraying methods as

\footnotetext{
* To whom correspondence should be addressed
} 
well as laser methods have been extensively used. They allow the strengthening of the surface by hardening or additional alloying (Chattopadhyay [1]; Fauchais and Vardelle [2]; Kwok [3]; Ion [4]).

Laser alloying can be used as well when new parts should be coated as when worn parts should be regenerated. Different materials may be used for this purpose: boron carbides (Yilbas et al. [5]; Mazahery and Shabani [6]; Feldshtein et al. [7]), tungsten carbides (Dobrzański et al. [8]), molybdenum and zirconium oxides ( $\mathrm{Ng}$ et al. [9]), $\mathrm{TiB}_{2}-\mathrm{TiC}-\mathrm{Al}_{2} \mathrm{O}_{3}$ type of composites (Masanta et al. [10]) and other. Many-component structures that are formed of additives affect the microhardness, stresses, wear and corrosion resistance.

The high cost and technological complexity of plasma spraying methods make them difficult to use for a single-part or small-quantity production. In this case, alloying materials can be deposited to parts in the form of coating based on the binders. Researches use different binders, that base on a paraffin, varnish, silicate glue, BF-6 glue, water glass, sodium polyacrylate/sodium silicate, liquid etanol, and so on (Sun et al. [11]; Patel and Morsi [12]; Chen et al. [13]; Ma et al. [14]).

Ni-based, Co-based and Fe-based self-fluxing alloys are one of the most commonly used coating materials (Vencl et al. [15]; Hemmati et al. [16]; Hamatani et al. [17]; Akebono et al. [18]; Fernández et al. [19]). The Ni- and Co-based alloys have very good overall properties but their main disadvantage is the high cost. If the properties of Fe-based alloys were enhanced, the Ni- and Co-based self fluxing alloys would be replaced by Fe-based alloys which have a high wear resistance and are relatively cheap [Vencl et al. [15]; Piao et al. [20], [21]; Weng et al. [22]; Yang [23]).

The bonding strength is one of the most important properties of coatings as it plays crucial roles in the performance and lifetime of them. So, a lot of research is devoted to this problem. Tests introduced by Peng et al. [24] explore different factors that affect the bonding strength of the Fe48Mo14Cr15Y2C15B6 amorphous coating prepared by high velocity oxygen fuel (HVOF) thermal spraying. The bonding strength of composite $\mathrm{Al}-\mathrm{Al}_{2} \mathrm{O}_{3}$ coatings built by cold spraying method was tested by Winnicki et al. [25] and the influence of thickness, roughness and waviness on the adhesive and cohesive properties of composite coatings was analyzed. The influence of ceramic thickness on residual stress and bonding strength for plasma sprayed duplex thermal barrier coating on aluminum alloy was described by Gu et al. [26]. It was found that with the increase of ceramic thickness, the residual stress in both layers was firstly compressive then turned tensile. The large thermal expansion coefficient of the substrate played an important role in residual stress formation when the ceramic was thin. The bonding strength decreased and the location of the fractured surface moved toward the ceramic surface. The effect of spraying power on the microstructure and bonding strength of $\mathrm{MoSi}_{2}$-based coatings was studied by $\mathrm{Wu}$ et al. [27]. The results demonstrated that coatings become more and more compact and the bonding strength increases when the spraying power increases. As the spraying power is of sufficient magnitude, many cracks and pores reappear in coatings and the bonding strength between coating and substrate also decreases. The stud-pull tests realized by Liang et al. [28] showed that the bonding strength in the as-sprayed surface mechanical attrition treatment (SMAT) sample is $\sim 30 \%$ higher than that in the as-sprayed coarse-grained sample. It was found that the enhanced bonding property of the $\mathrm{Zn}-\mathrm{Al}$ coating on the SMAT sample might be related with the promoted atomic diffusion and hardness in the nanostructured surface layer. The possibility of adhesion/cohesion bonding strength evaluation of thick plasma spray coatings was analyzed by Vencl et al. [29]. It was found that for Fe-based, Mo- based and $\mathrm{WC}-\mathrm{Co}-$ based coatings a direct comparison of the tensile bond strength and the scratch test results is questionable although a general trend exists that a higher elasticity modulus implies higher tensile bond strength and higher scratch bond strength. Wu et al. [30] described the single-ceramic-layer $\mathrm{Sm}_{2} \mathrm{Zr}_{2} \mathrm{O}_{7}$ and double-ceramic-layer $\mathrm{Sm}_{2} \mathrm{Zr}_{2} \mathrm{O}_{7} / 8 \mathrm{YSZ}$ thermal barrier coatings that were deposited by atmospheric plasma spraying on nickel-based superalloy substrates with NiCoCrAlY as the bond coat. It was found that the bonding strength of the second coating exhibits an average value approximately 1.5 times higher than that of the first layer, due to the combination of compact columnar and fine equiaxed structures. Tian et al. [31] determined the variation of adhesive bond strength of cold sprayed 7075 and 7050 aluminium alloy coatings on 7050-T7351 Al alloy substrate with coating thickness. Generally, without heating the substrate, the shear bond strength decreases with the increase in cold sprayed coating thickness. It is noted, inter-splat bonding dominates the properties and performance of thermally sprayed metallic coatings. The results show that the NiCr-Mo coating presents much dense structure with remarkably improved cohesion and adhesion 
strength in comparison with conventional $\mathrm{NiCr}$ coating. Higher bonding strength results from the formation of metallurgical bonding at the interfaces both between substrate and coating, and between lamellae.

To expand the available research information, the aim of the present paper was to study the bonding strength of Fe-based self-fluxing alloy coating deposited by plasma spraying, gluing and laser remelting and alloying on the steel substrate.

\section{Experimental procedure}

The Cr4Mn2B4Si2V1 powder of the Fe-Cr-B-Si system was used for coating (Tab.1). The AISI 5140 (EN 41Cr4) steel was used as the substrate material.

Table 1. Chemical composition of Cr4Mn2B4Si2V1 powder.

\begin{tabular}{|c|c|c|c|c|}
\hline \multicolumn{5}{|c|}{ Elements (wt \%) } \\
\hline $\mathrm{Fe}$ & $\mathrm{B}$ & $\mathrm{Cr}$ & $\mathrm{Si}$ & $\mathrm{Mn}$ \\
\hline Base & $3.3-4.3$ & $3.5-4.5$ & $2.0-2.5$ & $2.0-2.5$ \\
\hline \multicolumn{5}{|c|}{ Elements (wt \%) } \\
\hline $\mathrm{C}$ & $\mathrm{V}$ & $\mathrm{Al}$ & $\mathrm{Cu}$ \\
\hline $1.0-1.2$ & $0.5-0.9$ & $0.05-0.5$ & $0.05-0.5$ \\
\hline
\end{tabular}

For additional laser alloying boron carbide $\mathrm{B}_{4} \mathrm{C}$ was used that is characterized by high hardness, a high abrasion and wear resistance, high heat resistance.

Two methods have been used to deposit coating on the substrate: plasma spraying and gluing. Initial surfaces of samples were subjected to grit blasting and after that the coatings were deposited. In the first case, the UPU-3D plasma spray unit was used for coating with a plasma gun. This unit provides the deposition of a wide range of various powder materials: carbides, silicides, oxides, self-fluxing alloys, etc. Nitrogen under pressure of $0.6 \mathrm{MPa}$ was used as the plasma-forming gas. Spraying was carried out in the following conditions: the current $280 \mathrm{~A}$ and the voltage $70 \mathrm{~B}$. The coating thickness of $0.6 \mathrm{~mm}$ was provided.

In the second case, a paste which contained a self-fluxing alloy powder and an adhesive was deposited on samples. The nitrocellulose adhesive AGO was used as the binder. The paste was prepared by mixing three components: $3 \%$ glue AGO, acetone and P-Cr4Mn2B4Si2V1 powder to the consistency of thick cream. When coating layer was deposited on the surface of the sample, it was kept in air at room temperature for 1 hour to completely remove the solvent from the adhesive layer. The thickness of the coatings was kept constant and equal about $0.6 \mathrm{~mm}$.

After deposition, the samples were remelted with flame or a laser beam. Flame remelting consisted in applying an oxyacetylene flame to the coating until the melting temperature of the powder was reached. It was observed visually and controlled by a pyrometer.

The LGN-702 $\mathrm{CO}_{2}$ continuous-action laser with the power of $800 \mathrm{~W}$ was used for laser remelting. Different beam scanning speeds were used and the nitrogen acted as the drag gas. The laser beam diameters of $1.0 \mathrm{~mm}$ and $3.0 \mathrm{~mm}$ were used, which corresponds to a power density of about $1 \cdot 10^{5} \mathrm{~W} / \mathrm{cm}^{2}$ and $1.15 \cdot 10^{4}$ $W / \mathrm{cm}^{2}$. In order to obtain a uniform phase composition and the desired properties across the coating thickness, the beam overlap factors of 0.8 and 1.2 were used.

In the case of additive laser alloying, the paste based on $75 \mathrm{vol} \% \mathrm{~B}_{4} \mathrm{C}$ particulates, $3 \% \mathrm{AGO}$ adhesive and acetone was hand-brushed on the samples and then was deposited on them. Boron carbides $\left(\mathrm{B}_{4} \mathrm{C}\right)$ are characterized by high hardness, a high abrasion and wear resistance as well as high heat resistance. The stable thickness of $0.1 \pm 0.02 \mathrm{~mm}$ was provided.

A Magnetic Thickness Tool was used for coating thickness measurements. The ultrasonic surface thickness gauge 38DL PLUS was used for thickness measurements of the add-in $\mathrm{B}_{4} \mathrm{C}$ layer.

The structures of the coatings were studied using a metallographic microscope. 
The bonding strength of the coatings was examined using the RIEHLE tester. Its action is based on the ASTM C633 standard that was especially designed for plasma-sprayed coatings. To obtain more reliable values, 5 samples were tested and the average values are taken.

The bonding strength of the coatings $\sigma_{\mathrm{d}}$ was calculated as follows:

$$
\sigma_{d}=\frac{F}{S}
$$

To investigate the effect of coating methods a two-level full factorial design of $2^{3}$ type was used (Tab.2).

Table 2. The matrix of $2^{3}$ factorial design.

\begin{tabular}{|c|r|c|c|c|c|c|}
\hline \multirow{2}{*}{$\mathrm{Nr}$} & \multicolumn{2}{|c|}{ Laser beam speed } & \multicolumn{2}{c|}{ Laser beam diameter } & \multicolumn{2}{c|}{ Overlap ratio } \\
\cline { 2 - 7 } & Code & Value, mm/min & Code & Value, $\mathrm{mm}$ & Code & Value \\
\hline 1 & -1 & 50 & -1 & 1 & -1 & 0.8 \\
\hline 2 & 1 & 150 & -1 & 1 & -1 & 0.8 \\
\hline 3 & -1 & 50 & 1 & 3 & -1 & 0.8 \\
\hline 4 & 1 & 150 & 1 & 3 & -1 & 0.8 \\
\hline 5 & -1 & 50 & -1 & 1 & 1 & 1.2 \\
\hline 6 & 1 & 150 & -1 & 1 & 1 & 1.2 \\
\hline 7 & -1 & 50 & 1 & 3 & 1 & 1.2 \\
\hline 8 & 1 & 150 & 1 & 3 & 1 & 1.2 \\
\hline
\end{tabular}

The $\bar{X}_{i}$ mathematical processing of the results and their graphical interpretation was performed using Statistica 12 software.

\section{Result of research}

\subsection{Coatings characterization}

Remelting conditions have a significant impact on the morphology of the coatings because $\mathrm{FeCrBSi}$ alloys are structurally sensitive to the energy impact and to the alloying additives. Figure 1 shows the microstructures of coatings after plasma spraying and follow-up remelting with the flame burner and the laser beam.

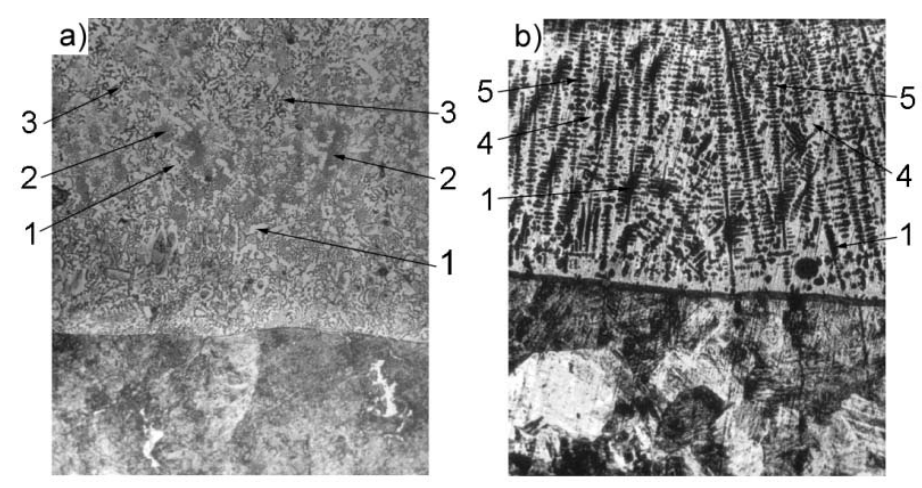

Fig.1. Microstructure of the Cr4Mn2B4Si2V1 coating after plasma spraying and remelting: a) the flame burner, b) the laser beam at a rate of $50 \mathrm{~mm} / \mathrm{min}(\times 400)$. 
It is easy to see the microstructure differences. When flame melting (Fig.1a) volumetric heating of the part occurs at which the coating is in a molten state long enough, 5-10 s. During this time, the complete crystallization of the coating and its cooling takes place. A globular structure is formed, which is based on grains of the Fe-based solid solution (1). Against the background of the solid solution carbide-boride phases (2) are clearly distinguishable, between which the $\mathrm{Fe}-\mathrm{Fe}_{2} \mathrm{~B}$ and $\mathrm{Fe}-\mathrm{FeB}$ eutectic colonies (3) are situated. The presence of both types of borides was determined by X-ray analysis.

Laser melting (Fig.1b) leads to the formation of metastable structures, reinforced with dendrites of the first, second and third order (5), consisting of alloyed Fe- $\alpha$ and Fe- $\gamma$ (1). The fine eutectic (4) is formed between the axes of the dendrites.

The structures of the coatings which were molten at various speeds of the laser beam are shown in Fig.2. The beam overlap factor 0.8 at a power density of the laser beam $1 \cdot 10^{5} \mathrm{~W} / \mathrm{m}^{2}$ was used. At speeds of 50 and $100 \mathrm{~mm} / \mathrm{min}$ the dendritic structures with the axes of the first and second orders (5) were observed.

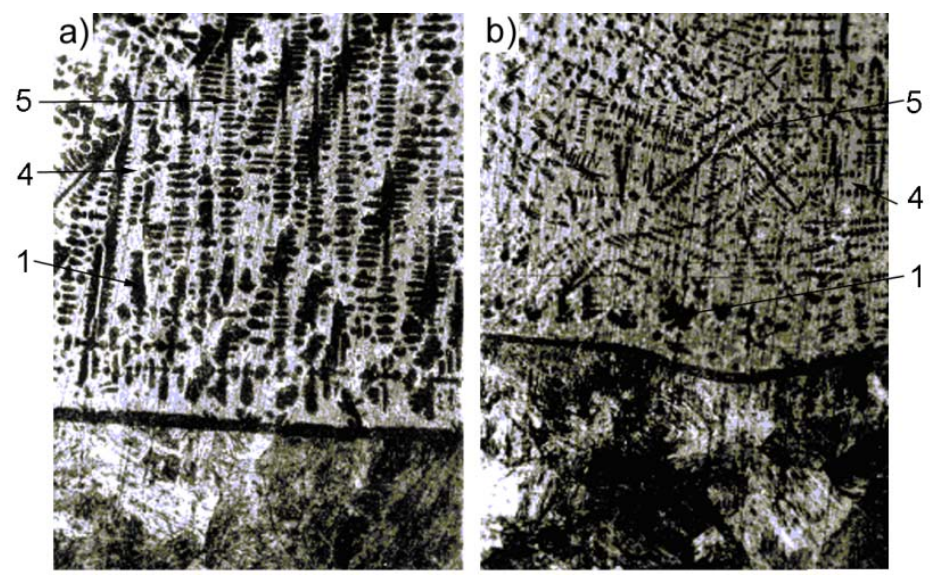

Fig.2. Coating microstructures after laser remelting with different laser beam speeds: a) $50 \mathrm{~mm} / \mathrm{min}$, b) $100 \mathrm{~mm} / \mathrm{min}$.

The Fe-based solid solution (1) is found between dendrites. At the lowest speed of the laser beam the coating was exposed to conditions of laser heating for a long time and the rates of crystallization of carbide and boride phases and $\mathrm{Fe}-\alpha$ solid solution (1) were aligned. The coating was melted completely with the formation of a cast structure with the axes of the dendrites of the first, second and third order (Fig.2a). When the laser beam speed is increased and the time, in which the coating is in the molten state, is reduced, the dendritic structure gets fragmented (Fig.2b).

The study of structures of coatings alloyed with $\mathrm{B}_{4} \mathrm{C}$ and remelted by the laser beam showed that they vary with the increase of the spot speed. At a speed of $50 \mathrm{~mm} / \mathrm{min}$ a cast equilibrium cellular structure with splashes of dendrites is formed (Fig.3a). This is an evidence of a rather long stay of the coating in the laser irradiation zone that led to the redistribution of elements in the coating. When the spot speed is increased, the time of the remelting action is reduced. When the speed increases up to $100 \mathrm{~mm} / \mathrm{min}$, dendrites appear in the structure, with first-order axes oriented at $45^{\circ}$ to the direction of the heat sink (Fig. $3 \mathrm{~b}$ ).

The SEM analysis found that when the spot speed is equal to $50 \mathrm{~mm} / \mathrm{min}$, small dendrites are the predominant structure, whose axes are oriented in the direction of the heat sink (Fig.3a). At higher speeds, the structure is a supersaturated solid solution with precipitates of carbides and borides of sizes up to $\sim 6$ microns (Fig.3b). 

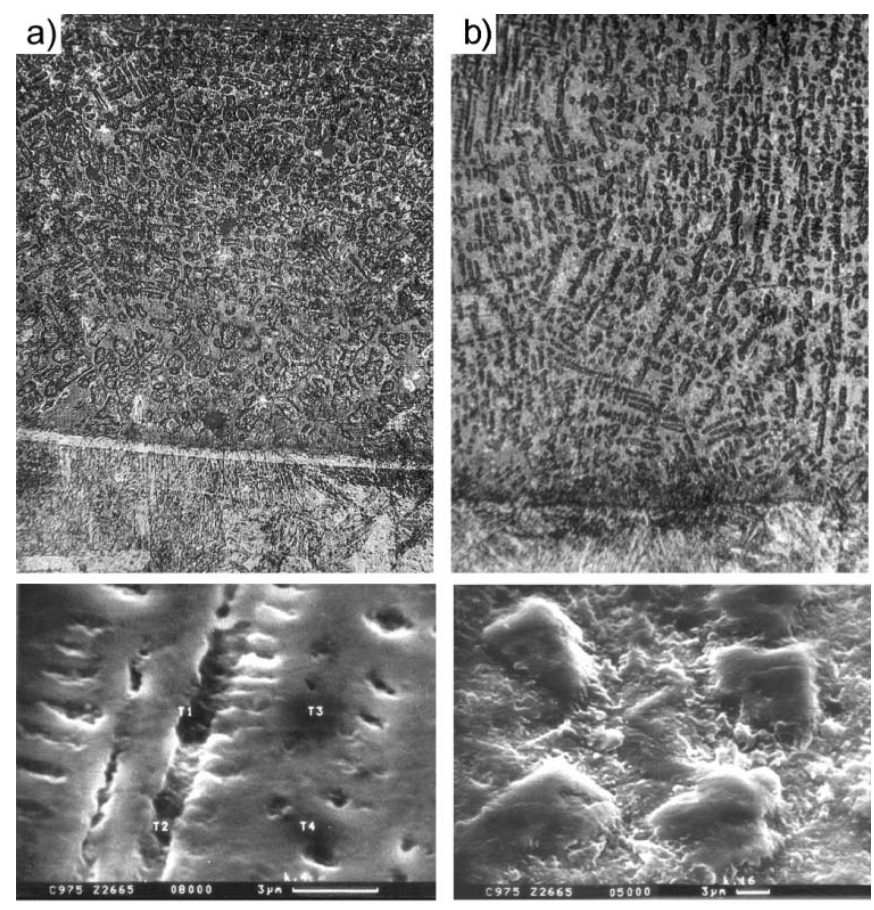

Fig.3. Reinforced adhesive coating microstructures and SEM images after laser alloying with $\mathrm{B}_{4} \mathrm{C}$ particulates with different spot speeds: a) $50 \mathrm{~mm} / \mathrm{min}$, b) $100 \mathrm{~mm} / \mathrm{min}$.

\subsection{The bonding strength of tested coatings}

While testing the bonding strength of the reinforced glue coating, adhesive and adhesive-cohesive character of the samples breaking were observed. The first case is characteristic for high laser beam speeds and the coating have been broke completely, and in the second case, some of coating remained on the substrate. The destruction of the coating began from the sample edges, where the thickness of the adhesive layer is smaller and there are defects, i.e., there is no satisfactory contact of the adhesive with the material. Considerable stresses are concentrated in these places. While the load increases in the coating, microcracks develop, which gradually spread to the center of the bonding surface. When the number of microcracks reaches a certain level, conditions are created for their joining into a crack of considerable size, which leads to the destruction of the bonding surface.

The performed calculations made it possible to determine the regression equation for calculating the bonding strength for a glue coating reinforced with $\mathrm{B}_{4} \mathrm{C}$ particulates

$$
\sigma_{d}=90.76-25.17 X_{1}-9.83 X_{2}-10 X_{3}+2.58 X_{1} X_{2}+3.24 X_{2} X_{3} .
$$

The coefficient of determination (In statistics, the coefficient of determination, denoted $R^{2}$ )of this equation is close to 1.0. The numerical values of the codes for arbitrary values of laser beam speed, laser beam diameter, and overlap ratio are determined by the equations

$$
X_{i}=\frac{X_{i}-\bar{X}_{i}}{m_{i}} ; \quad \bar{X}_{i}=\frac{X_{i \max }+X_{i \min }}{2} ; \quad m_{i}=\frac{X_{i \max }-X_{i \min }}{2} .
$$

The effect of the parameters and technologies of coatings on their bonding strength is shown in Figs 4, 5 . 

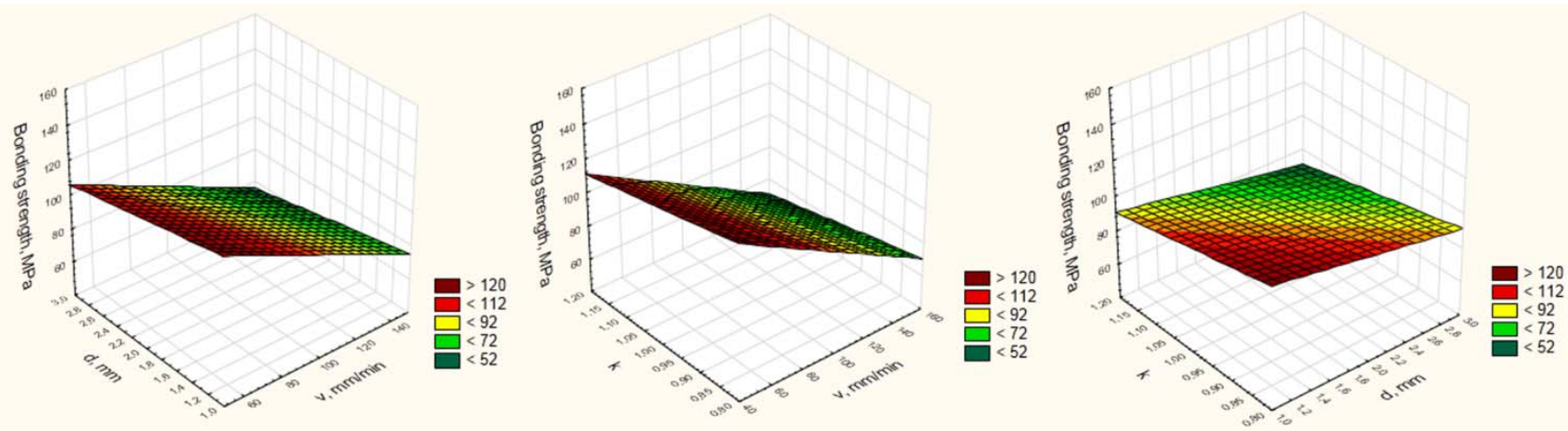

Fig.4. The influence of laser remelting conditions on bonding strength of glued reinforced $\mathrm{B}_{4} \mathrm{C}$ coatings.

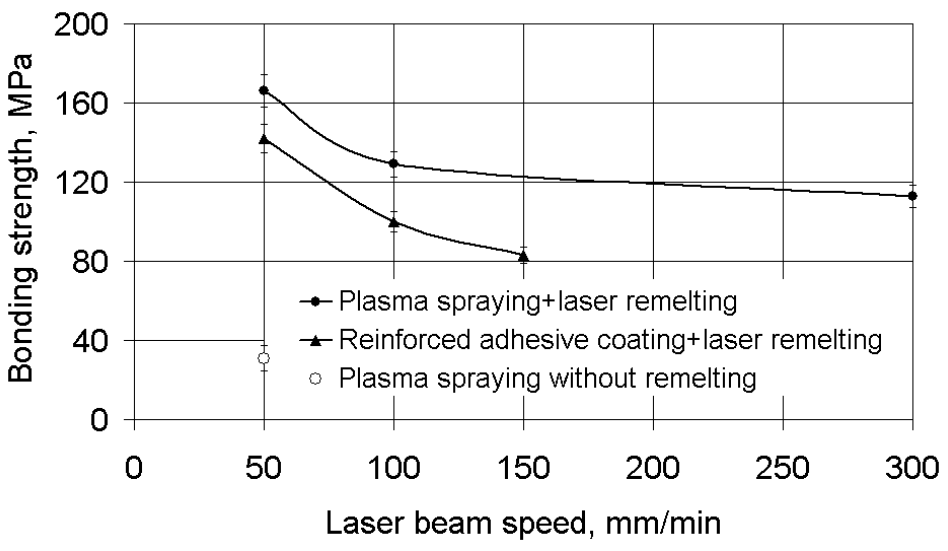

Fig.5. The effect of coating technology on the bonding strength.

Based on the analysis of the results obtained, it can be argued that coating without subsequent remelting has a negative effect: the bonding strength decreases by $4-5$ times due to the presence of pores and a significant amount of oxide films in the coating.

For plasma coatings after laser remelting without additional alloying, the $\sigma_{\mathrm{d}}$ maximum value is observed with the minimum laser beam speed. With increasing the laser beam speed to $300 \mathrm{~mm} / \mathrm{min}, \sigma_{d}$ decreases almost 1.5 times. This is due to structural changes in the coating as a result of the reduction in the time of the part stay in the zone of laser heating.

In glue coatings reinforced with $\mathrm{B}_{4} \mathrm{C}$ particulates, the bonding strength is lower by 1.2-1.4 times in comparison with plasma coating. Higher bonding strength in remelted coatings is also observed at low laser beam speeds in this case. The laser beam diameter and the overlap ratio - (A new method for registration of $3 \mathrm{D}$ point sets with low overlapping ratios) are significantly weaker in comparison with the effect of a speed.

\section{Conclusions}

1. The bonding strength of Fe-based self-fluxing alloy coating deposited by plasma spraying, gluing and laser remelting and alloying on the steel substrate have been investigated. Remelting conditions have a significant impact on the morphology of the coatings. When flame melting, a globular structure is formed, which is based on grains of the Fe-based solid solution. Against the background of the solid solution carbide-boride phases are clearly distinguishable, between which the $\mathrm{Fe}-\mathrm{Fe}_{2} \mathrm{~B}$ and $\mathrm{Fe}-\mathrm{FeB}$ eutectic colonies are situated. 
2. Laser remelting leads to the formation of metastable structures, reinforced with dendrites, consisting of alloyed Fe- $\alpha$ and Fe- $\gamma$. At the low laser beam speeds the coating is melted completely with the formation of a cast structure with the dendrites. When the laser beam speed is increased, the dendritic structure gets fragmented.

3. Structures of coatings alloyed with $\mathrm{B}_{4} \mathrm{C}$ and remelted by the laser beam vary with the increase of the spot speed. At a speed of $50 \mathrm{~mm} / \mathrm{min}$ a cast equilibrium cellular structure with splashes of dendrites is formed. When the speed increases up to $100 \mathrm{~mm} / \mathrm{min}$, dendrites appear in the structure, with first-order axes oriented at $45^{\circ}$ to the direction of the heat sink.

4. The bonding strength of the reinforced glue coating has adhesive and adhesive-cohesive character. The destruction of the coating begins from the sample edges, where the thickness of the adhesive layer is smaller and there are defects. When the load increases in the coating, microcracks develop, which gradually spread to the center of the bonding surface. The bonding strength of coating without subsequent remelting decreases by 4-5 times in comparison with remelted coating due to the presence of pores and a significant amount of oxide films in the coating.

5. For plasma coatings after laser remelting without additional alloying, the maximum bonding strength is observed with the minimum laser beam speed. With increasing the laser beam speed it decreases almost 1.5 times. In glue coatings reinforced with $\mathrm{B}_{4} \mathrm{C}$ particulates by laser remelting, the bonding strength is lower by 1.2-1.4 times in comparison with plasma coating. Higher bonding strength is also observed at low laser beam speeds.

\section{Nomenclature}

$D$ - a laser beam diameter

$F$ - a largest force recorded by the testing machine, Eq.(2.1)

$K-$ an overlap ratio

$m_{i}$ - a step for $i$ factor that was coded, Eq.(3.2)

$S$ - a cross-sectional area of the coated specimens, Eq.(2.1)

$\sigma_{d}-$ a bonding strength of the coatings, Eq.(2.1)

$V$ - a laser beam speed

$X_{1}, X_{2}, X_{3}$ - codes for laser beam speed, laser beam diameter and overlap ratio, Eq.(3.1)

$\bar{X}_{i} \quad-$ an average value for $i$ factor that was coded, Eq.(3.2)

\section{References}

[1] Chattopadhyay R. (2004): Advanced Thermally Assisted Surface Engineering Processes. - Kluwer Academic Publisher, Dordrecht.

[2] Fauchais P. and Vardelle A. (2012): Thermal sprayed coatings used against corrosion and corrosive wear. - In: Advanced Plasma Spray Applications, H.S. Jazi (Ed.). InTech, Rijeka, pp.3-38.

[3] Kwok C.T. (Ed.) (2012): Laser surface modification of alloys for erosion and corrosion resistance. - Woodhead Publishing Ltd, Cambridge.

[4] Ion J.C. (2005): Laser processing of engineering materials. principles, procedure and industrial application. Chapter 12 - Cladding. - Elsevier Butterworth-Heinemann Linacre House, Burlington, pp.296-326.

[5] Yilbas B.S., Patel F., Karatas C. (2013): Laser controlled melting of HSLA steel surface with presence of B ${ }_{4} C$ particles. - Appl. Surf. Sci. - vol.282, pp.601-606.

[6] Mazahery A., Shabani M.O. (2012): Influence of the hard coated $\mathrm{B}_{4} \mathrm{C}$ particulates on wear resistance of $\mathrm{Al}-\mathrm{Cu}$ alloys. - Comp.: Part B. - vol.43, No.3, pp.1302-1308. 
[7] Feldshtein E.E., Kardapolava M.A. and Dyachenko O.V. (2015): Microstructure and phase composition of Febased self-fluxing alloy coatings formed by laser remelting and superficially modified by laser alloying with $B_{4} C$ particulates. - Kovové Materiály = Metal. Mater. - vol.53, No.3, pp.155-159.

[8] Dobrzański L.A., Bonek M., Hajduczek E. and Klimpel A. (2005): Alloying the X40CrMoV5-1 steel surface layer with tungsten carbide by the use of a high power diode laser. - Appl. Surf. Sci. - vol.247, No.1-4, pp.328-332.

[9] Ng K.W., Man H.C. and Yue T.M. (2008): Corrosion and wear properties of laser surface modified NiTi with Mo and $\mathrm{ZrO}_{2}$. - Appl. Surf. Sci. - vol.254, No.21, pp.6725-6730.

[10] Masanta M., Shariff S.M. and Choudhury A.R. (2011): A comparative study of the tribological performances of laser clad $\mathrm{TiB}_{2}-\mathrm{TiC}-\mathrm{Al}_{2} \mathrm{O}_{3}$ composite coatings on AISI 1020 and AISI 304 substrates. - Wear. - vol.271, No.7-8, pp.1124-1133.

[11] Sun G., Zhou R., Li P., Feng A. and Zang Y. (2011): Laser surface alloying of C-B-W-Cr powders on nodular cast iron rolls. - Surf. Coat. Technol. - vol.205, No.8-9, pp.2747-2754.

[12] Patel J. and Morsi K. (2012): Effect of mechanical alloying on the microstructure and properties of Al-Sn-Mg alloy. - J. Alloys Compd. - vol.540, pp.100-106.

[13] Chen G.Q., Li N.N., Fu X.S. and Zhou W.L. (2012): Preparation and characterization of a sodium polyacrylate/sodium silicate binder used in oxidation resistant coating for titanium alloy at high temperature. Powder Technol. - vol.230, pp.134-138.

[14] Ma Q., Gao X. and Li J. (2016): Microstructure performance and formation mechanism of laser alloying rare earth oxides modified nanocrystalline layer on TA7. - Physica E: Low-Dimen. Syst. Nanostruct. - vol.77, pp.29-33.

[15] Vencl A., Mrdak M. and Cvijović I. (2006): Microstructures and tribological properties of ferrous coatings deposited by APS (Atmospheric Plasma Spraying) on Al-alloy substrate. - FME Trans. - vol.34, No.3, pp.151-157.

[16] Hemmati I., Huizenga R.M., Ocelík V. and De Hosson J.Th.M. (2013): Microstructural design of hardfacing NiCr-B-Si-C alloys. - Acta Mater. - vol.61, pp.6061-6070.

[17] Hamatani H., Ichiyama Y. and Kobayashi J. (2002): Mechanical and thermal properties of HVOF sprayed Ni based alloys with carbide. - Sci. Technol. Adv. Mater. - vol.3, No.4, pp.319-326.

[18] Akebono H., Komotori J. and Suzuki M. (2006): The effect of coating thickness on fatigue properties of steel thermally sprayed with N-based self-fluxing alloy. - Int. J. Mod. Phys. B. - vol.20, No.25n27, pp.3599-3604.

[19] Fernández E., Cadenas M., González R., Navas C., Fernández R. and De Damborenea J. (2005): Wear behaviour of laser clad NiCrBSi coating. - Wear. - vol.259, pp.870-875.

[20] Piao Z., Xu B., Wang H. and Wen D. (2013) Influence of surface nitriding treatment on rolling contact behavior of Fe-based plasma sprayed coating. - Appl. Surf. Sci. - vol.266, pp.420-425.

[21] Weng Z., Wang A., Wang Y., Xiong D. and Tang H. (2016): Diode laser cladding of Fe-based alloy on ductile cast iron and related interfacial behavior. - Surf. Coat. Technol. - vol.286, pp.64-71.

[22] Yang X.-Y., Peng X., Chen J. and Wang F. (2007): Effect of a small increase in the Ni content on the properties of a laser surface clad Fe-based alloy. - Appl. Surf. Sci. - vol.253, No.9, pp.4420-4426.

[23] Piao Z., Xu B., Wang H. and Wen D. (2013) Characterization of Fe-based alloy coating deposited by supersonic plasma spraying. - Fusion Eng. Des. -vol.88, No.11, pp.2933-2938.

[24] Peng Y., Zhang C., Zhou H. and Liu L. (2013): On the bonding strength in thermally sprayed Fe-based amorphous coatings. - Surf. Coat. Technol. - vol.218, pp.17-22.

[25] Winnicki M., Małachowska A., Piwowarczyk T., Rutkowska-Gorczyca M. and Ambroziak A. (2016): The bond strength of $\mathrm{Al}+\mathrm{Al}_{2} \mathrm{O}_{3}$ cermet coatings deposited by low-pressure cold spraying. - Arch. Civil Mech. Eng. vol.16, pp.743-752.

[26] Gu L., Fan X., Zhao Y., Zou B., Wang Y., Zhao S. and Cao X. (2012): Influence of ceramic thickness on residual stress and bonding strength for plasma sprayed duplex thermal barrier coating on aluminum alloy. - Surf. Coat. Technol. - vol.206, pp.4403-4410. 
[27] Wu H., Li H., Lei Q., Fu Q., Ma C., Yao D., Wang Y., Sun C., Wei J. and Han Z. (2011): Effect of spraying power on microstructure and bonding strength of $\mathrm{MoSi}_{2}$-based coatings prepared by supersonic plasma spraying. Appl. Surf. Sci. - vol.257, No.13, pp.5566-5570.

[28] Liang Y.L., Wang Z.B., Zhang J., Zhang J.B. and Lu K. (2016): Enhanced bonding property of cold-spayed Zn-Al coating on interstitial-free steel substrate with a nanostructured surface layer. - Appl. Surf. Sci. - vol.385, No.13, pp.341-348.

[29] Vencl A., Arostegui S., Favaro G., Zivic F., Mrdak M., Mitrović S. and Popovic V. (2011): Evaluation of adhesion/cohesion bond strength of the thick plasma spray coatings by scratch testing on coatings cross-sections. Trib. Int. - vol.44, pp.1281-1288.

[30] Wu H.X., Ma Z., Liu L., Liu Y.B. and Wang D.Y. (2016): Thermal cycling behavior and bonding strength of single-ceramic-layer $\mathrm{Sm}_{2} \mathrm{Zr}_{2} \mathrm{O}_{7}$ and double-ceramic-layer $\mathrm{Sm}_{2} \mathrm{Zr}_{2} \mathrm{O}_{7} / 8 \mathrm{YSZ}$ thermal barrier coatings deposited by atmospheric plasma spraying. - Ceramics Int. -vol.42, No.11, pp.12922-12927.

[31] Tian J., Yao S., Luo X., Li C. and Li C. (2016): An effective approach for creating metallurgical self-bonding in plasma-spraying of NiCr-Mo coating by designing shell-core structured powders. - Acta Mater. - vol.110, pp.19-30.

Received: April 19, 2017

Revised: March 2, 2018 